\title{
From evidence to best practice in the management of fractures of the distal radius in adults: working towards a research agenda Helen HG Handoll* and Rajan Madhok
}

\author{
Address: Research and Development Office, School of Health and Social Care, University of Teesside, Middlesbrough, TS1 3BA, UK \\ Email: Helen HG Handoll* - h.handoll@ed.ac.uk; Rajan Madhok - rajan.madhok@neynlha.nhs.uk \\ * Corresponding author
}

Published: 27 November 2003

BMC Musculoskeletal Disorders 2003, 4:27
Received: 24 July 2003

Accepted: 27 November 2003

This article is available from: http://www.biomedcentral.com/I47/-2474/4/27

(C) 2003 Handoll and Madhok; licensee BioMed Central Ltd. This is an Open Access article: verbatim copying and redistribution of this article are permitted in all media for any purpose, provided this notice is preserved along with the article's original URL.

\begin{abstract}
Background: Fracture of the distal radius is a common clinical problem, particularly in older white women with osteoporosis. We report our work towards evidence-based and patient-centred care for adults with these injuries.
\end{abstract}

Methods: We developed a systematic programme of research that built on our systematic review of the evidence of effectiveness of treatment interventions for these fractures. We devised schemata showing 'typical' care pathways and identified over 100 patient management questions. These depicted the more important decisions taken when progressing along each care pathway. We compiled a comprehensive document summarising the evidence available for each decision point from our reviews of randomised trials of treatment interventions. Using these documents, we undertook a formal and structured consultation process involving key players, including a patient representative, to obtain their views on the available evidence and to establish a research agenda. The resulting feedback was then processed and interpreted, using systematic methods.

Results: Some evidence from II4 randomised trials was available for 31 of the 117 patient management questions. However, there was sufficient evidence to base some conclusions of effectiveness for particular interventions in only five of these.

Though only $60 \%$ of those approached responded, the responses received from the consultation group were often comprehensive and provided important insights into treatment practice and policy. There was a clear acceptance of the aims of the project and, aside from some suggestions for the more explicit inclusion of secondary prevention and management of complications, of the care pathways scheme. Though some respondents stressed that randomised trials were not always appropriate, there was no direct overall criticism of the evidence document and underlying processes. We were able to identify important core themes that underpin management decisions and research from the feedback of the consultation exercise.

Conclusions: Overall, this project is an important advance towards evidence-based and patientcentred management of adults with distal radial fractures. It exposes the serious deficiency in the available evidence but also provides a template for further action. As well as being a valuable basis for viewing and informing current practice, the insights gained from this project should inform a future research agenda. 


\section{Background \\ Distal radial fractures}

Fracture of the distal radius is one of the most common fractures in many predominantly white and older populations [1,2]. It has been estimated that, at 50 years of age, a white woman in USA or Northern Europe has a 15\% lifetime risk of a distal radius fracture; whereas a man has a lifetime risk of just over 2\% [3]. A recent prospective survey of Colles' fracture in patients aged 35 years and above, in six centres in the UK, reported the overall annual incidence of this fracture to be $9 / 10,000$ in men and 37/ 10,000 in women [4]. Distal radial fractures are usually treated on an outpatient basis with around $20 \%$ of patients (mainly older people) requiring hospital admission $[3,4]$.

Most fractures of the distal radius in older people result from low-energy trauma, such as a fall from standing height or less. The pattern of incidence generally reflects the bone loss from osteoporosis and, particularly in women, an increased number of falls in older people $[5,6]$.

These fractures, which are usually closed (the skin remains intact), usually involve the displacement of fracture fragments, and may involve disruption of the articular or joint surfaces of the distal radius. Numerous classifications have been devised to define and group different fracture patterns [7]. "Colles' fracture", with a characteristic 'dinner-fork' deformity, is the term used for the most common variety. Colles' fracture is recognised to be an indicator of the risk of further fractures, notably hip fracture.

The majority of distal radial fractures are treated conservatively (non-operatively). This usually involves the reduction under anaesthesia of the fracture, if displaced, and forearm immobilisation in a plaster cast or brace. Surgical treatment involves either closed or open reduction followed by external or internal fixation and immobilisation. Aftercare usually consists of plaster cast management or pin track care and adjustment of external fixators, with monitoring of the fracture position, recovery and assessment of complications. Depending on the severity of the injury, immobilisation is generally around six weeks. The timing, extent and nature of rehabilitation are variable; more extensive rehabilitation generally being provided in response to complications, pain, stiffness and functional disability.

It has been long recognised that these injuries can result in increased morbidity, with long-term functional impairment, pain and deformity [8,9]. They are also associated with a high incidence and variety of complications; for example, serious complications, such as persistent neu- ropathies of the median, ulnar or radial nerves, have been reported in one in three patients [10]. Some complications can be directly attributed to treatment, notably pinsite infection for external fixators. A more recent paper has stressed that "not only hip fracture, but also wrist fractures may reduce older people's chances of remaining independent" [11].

\section{Systematic reviews of the evidence}

We have now completed a portfolio of systematic reviews, published in The Cochrane Library, of the evidence from relevant randomised controlled trials (RCTs). Our five reviews, which examine conservative and surgical treatments, anaesthesia and rehabilitation, cover all of the key interventions for the management of these fractures [1216].

Our work shows the insufficient and often inadequate evidence of effectiveness of commonly applied interventions and the unsatisfactory outcome of wrist fracture treatment for many patients $[17,18]$. The controversy over the management of Colles' fractures has also been stressed elsewhere [19]. There is thus a strong case for seeking ways to improve the management of these common osteoporotic fractures. Here, we report on our initiative to take further our systematic review of the evidence by placing it into the context of the care decisions made within a 'typical' care pathway and then, though a consultation exercise aimed at identifying key treatment questions and research priorities, establish a research agenda.

\section{Methods}

We identified the following key tasks towards our aims:

- Maintain and build on the underlying evidence base for treatment interventions.

- Develop a 'typical' care programme for patients presenting with distal radius fractures through to final recovery and subsequent management to prevent further fractures, and identify the key decision points.

- Compile a document matching the evidence with the decision points in the care programme.

- Undertake a formal consultation exercise involving key players to enable structured feedback on key issues and research priorities.

\section{Maintenance and consolidation of the evidence base}

We prepared five Cochrane reviews of the evidence from randomised controlled trials for the key interventions used in the management of these fractures using the methods for preparing systematic reviews detailed in the Cochrane Handbook [20]. A vital and continuing part of 
Table I: Categories of effectiveness (definitions)

\begin{tabular}{ll}
\hline Category & Definition \\
\hline Beneficial & $\begin{array}{l}\text { Interventions whose effectiveness has been demonstrated by clear evidence from randomised } \\
\text { controlled trials, and expectation of harms that is small compared with the benefits. } \\
\text { Interventions for which effectiveness is less well established than for those listed under "beneficial". } \\
\text { Likely to be beneficial } \\
\text { Trade off between benefits and harms }\end{array}$ \\
$\begin{array}{l}\text { Interventions for which clinicians and patients should weigh up the beneficial and harmful effects } \\
\text { according to individual circumstances and priorities. } \\
\text { Interventions for which there are currently insufficient data or data of inadequate quality. } \\
\text { Interventions for which lack of effectiveness is less well established than for those listed under "likely to } \\
\text { be ineffective or harmful". } \\
\text { Interventions whose ineffectiveness or harmfulness has been demonstrated by clear evidence. }\end{array}$ \\
\hline
\end{tabular}

our research programme is keeping these reviews up to date.

\section{Developing a 'typical' care programme and identifying important treatment questions}

We determined that our main focus would be on the care pathways for 'typical Colles' fracture patients'; namely, older people, usually female, with an osteoporotic fracture resulting from low energy trauma.

We devised a 'typical' care programme comprising several care pathways dependent on key decisions (such as whether to operate). This process drew on various sources, either directly such as published (e.g. [21]) and unpublished outline care pathways/protocols or indirectly through parallels with care pathways for other disorders. One key decision was to formulate the treatment questions allied to the various decision points in the care pathway. The multistage process for developing the care pathway was lengthy and featured several prototypes that were substantially revised after discussion and feedback from core project group members.

\section{Matching the evidence to the treatment choices and questions presented in the 'typical' care programme}

We knew already from our existing research that the underlying evidence was insufficient to establish the best methods for managing these fractures. We were also aware of serious problems with diagnostic methods, fracture classification, prognostic factors and outcome assessment. However, given the overall complexity of this area, we determined that our primary focus would be on treatment interventions and the gathering of evidence to inform the choice of treatment interventions. We stipulated beforehand that we would restrict our selves to evidence from RCTs: our resources were insufficient to allow us to consider other comparative study designs.

Drawing upon our extensive knowledge of the topic-specific research literature, we compiled a comprehensive document of the evidence for the various decision points, expressed in question form. The evidence document was structured by the pathways and associated questions portrayed in the full care pathway (see Results: Development of a 'typical' care programme). Where evidence from RCTs was available, summaries of the trial populations, the actual comparisons and results were provided. In addition, specific comments were given; mainly in explanation and support of the concluding interpretation of the (relative) effectiveness of each intervention. We stated beforehand that we would summarise the evidence using the same systematic processes as used by contributors to BMJ's Clinical Evidence [22]. Thus the relative effectiveness of the interventions was graded according to the six categories described in Table 1.

\section{The consultation process}

To obtain critical feedback on our findings and the above products of our project, and to identify key issues and research priorities, we chose a comprehensive one-stage consultation exercise. We considered this would enable effective participation without placing an excessive and unacceptable burden on the participants, most of whom are busy clinicians.

\section{Design of the questionnaire}

We designed a dual-purpose document to provide both a summary of the evidence and to enable structured feedback and grading of research priorities. The questionnaire was designed to be consistent with other documentation developed for the project but also 'standalone'. We included some opportunity for the examination of the possible impact of anticipated future developments (e.g. bone substitutes) and of subsequent management strategies to prevent future fractures.

\section{Selection of consultation group members}

We aimed to get a broad coverage of the specialities involved in the management of these fractures, and also consumer and international input. We identified people 
Table 2: Treatment questions where there is some underlying evidence of effectiveness

\begin{tabular}{|c|c|}
\hline Question & Evidence from RCTs \\
\hline $\begin{array}{l}\text { Comparison(s) tested within } \\
\text { the } R C T s^{*}\end{array}$ & $>$ Interpretation \\
\hline \multicolumn{2}{|l|}{$\begin{array}{l}\text { Q8 When is surgery indicated for definitive treatment (at } \\
\text { start)? }\end{array}$} \\
\hline \multirow[t]{2}{*}{ a. Percutaneous pinning versus plaster cast alone } & a. 5 RCTs, 363 participants \\
\hline & $\begin{array}{l}\text { Across fracture pinning 'likely to be beneficial' but circumstances not } \\
\text { established. (Unknown effectiveness: Kapandji pinning.) } \\
\text { b. I } 3 \text { RCTs, } 859 \text { participants; I } 33 \text { redisplaced fractures }\end{array}$ \\
\hline b. External fixation versus plaster cast alone & $\begin{array}{l}\text { External fixation is "likely to be beneficial" but indications (e.g. } \\
\text { fracture type) for treatment, and the type, technique and timing of } \\
\text { external fixation are not resolved. }\end{array}$ \\
\hline \multicolumn{2}{|l|}{ Q9.3 What method(s) of anaesthesia is preferable? } \\
\hline \multirow[t]{2}{*}{ a. Intravenous regional anaesthesia (IVRA) versus haematoma block } & a. 5 RCTs, 478 participants \\
\hline & $\begin{array}{l}\text { IVRA is probably more "likely to be beneficial" than haematoma } \\
\text { block. }\end{array}$ \\
\hline \multicolumn{2}{|l|}{ Q17.2 What type of pins should be used? } \\
\hline \multirow[t]{2}{*}{ Biodegradable rods / pins versus K-wires (for Kapandji / trans-fracture fixation) } & 2 RCTs, 70 participants \\
\hline & > Biodegradable implants "unlikely to be beneficial". \\
\hline \multicolumn{2}{|l|}{ Q18.I What method(s) of external fixation is / are preferable? } \\
\hline \multirow[t]{2}{*}{ a. Non-bridging (of wrist joint) versus bridging external fixation } & a. 2 RCTs, 80 participants \\
\hline & $\begin{array}{l}\text { Non-bridging external fixation 'likely to be beneficial' when able to } \\
\text { place distal pin securely. (Evidence for predominantly redisplaced } \\
\text { fractures.) }\end{array}$ \\
\hline \multicolumn{2}{|l|}{ Q19.I What method(s) of internal fixation is / are preferable? } \\
\hline \multirow[t]{2}{*}{ Pi-plate versus $2 \mathrm{l} / 4$ tube plates } & I RCT, 65 participants \\
\hline & $\begin{array}{l}\text { Pi-plate "unlikely to be beneficial" in present form for smaller radii } \\
\text { due to operational difficulties in fitting the plate. }\end{array}$ \\
\hline
\end{tabular}

\footnotetext{
* Note that for multi-comparison questions (Q8; Q9.3; Q19.1), only the comparisons yielding evidence are included here.
}

with known, or strongly suspected, interest in advancing research towards evidence-based practice for managing fractures of the distal radius. This included known authorities - such as those producing seminal works on the treatment of these fractures - and opinion leaders. Also included were trial investigators who had conducted one or more RCTs in the area. Some indication of continued relevant research activity and/or practice was sought for people whose RCTs were published more than five years ago. Some decisions for inclusion were based on whether a researcher had satisfactorily responded to a previous query about their trial. An internet search http://www.spe cialistinfo.com was also undertaken to identify specialist UK orthopaedic and trauma consultants with a special interest in wrist fractures. Up-to-date contact details were sought for each candidate.

The consultation

A letter introducing the study and giving advanced notice of the questionnaire was sent to all potential members of the consultation group. Upon preparation of the full documentation for the project, a covering letter plus enclosures (comprising the care pathways documents, the evidence document and questionnaire) were dispatched to members of the consultation group. A reminder was sent six to eight weeks later. This included a short questionnaire focusing on research priorities.

\section{Processing and interpreting the results of the consultation process}

In order to facilitate the comprehension and interpretation of the feedback provided by members of the consultation group, we prepared three documents. Two of these focussed on the specific responses to individual treatment questions provided in the questionnaire. The third document was a compilation of all extra feedback, including comments from respondents who did not complete the questionnaire.

Having rendered the feedback into a physically more manageable and accessible form, there remained the challenge of its interpretation. Essentially this involved both awareness and appraisal of the context (such as who responded) of the responses as well as setting the responses into the context of the project aims and materi- 
als. We decided on a broad-brush and structured approach comprising three stages.

In the first stage, we devised a prior list of basic questions to examine the response to the aims, processes and materials of the project.

In the next stage, we constructed a table of the research ratings for individual patient management questions provided in the questionnaires as well as recording the research priorities of questionnaire non-completers. Consistent with our essentially qualitative approach for the consultation exercise, only limited and simple quantitative analysis of the results of the consultation process was undertaken. We were constantly mindful of the risk of over-interpretation and avoided attempting quantitative assessment of measures of agreement/disagreement. However, to facilitate an exploration of the implications for a future research agenda, we set an arbitrary research rating threshold to identify a provisional list of high priority research topics from the list of patient management questions.

In the third stage, we considered further results of the consultation exercise in the context of four underlying questions:

- For whom - in terms of patient and fracture characteristics?

- What interventions should be provided?

- When should these provided and for how long?

- Who should provide these?

By this means, we attempted to identify some basic themes and issues.

\section{Results}

Maintenance and consolidation of the evidence base

Our production of a review on closed reduction methods [13], first published in Issue 1, 2003 of The Cochrane Library, completed our coverage of the main interventions for the management of these fractures. We have since completed substantive updates of our Cochrane reviews on conservative interventions (Issue 2, 2003) and surgical interventions (Issue 3, 2003), and minor updates, reflecting the absence of newly included trials, of our reviews covering rehabilitative interventions (Issue 2, 2003) and anaesthesia interventions (Issue 4, 2003). Notably, the comparisons in our review on conservative interventions [12] were restructured to reflect the decision points, and associated timing, for the management of these fractures. This was as a direct consequence of our consideration of care pathways undertaken as part of this project. Also incorporated in our updated reviews were details obtained from the consultation process of four ongoing or unpublished RCTs and important insights on an already included surgical trial.

\section{Development of a 'typical' care programme and identification of important treatment questions}

The resulting care programme, which focussed on the usual care pathways for 'typical' fracture patients (namely those sustaining a low trauma fracture indicative of osteoporotic bone), was presented in two documents. One ('Appendix 1 [see Additional file 1]') is a care pathways overview diagram showing the basic treatment choices, presented as questions (e.g. Reduce?; Surgery?), structured according to several pathways ('core' and 7 others) with some allowance for revision due to failed procedures and other reasons. The other was the full care pathways document showing the various stages of the core and other treatment pathways ('Appendix 2 [see Additional file 2]'). As well as providing brief descriptions of key patient characteristics and/or reasons for some treatment choices, this listed 117 treatment questions (e.g. Q3.1 When should definitive treatment begin?) pertinent to the various stages.

\section{Matching the evidence to the treatment choices and questions presented in the 'typical' care programme}

This resulted in a comprehensive evidence document, which was structured by the pathways and associated questions portrayed in the care pathway. The evidence available from 114 RCTs included in our systematic reviews, up to Issue 1, 2003 of The Cochrane Library, was linked to the various decision points, expressed in question form, and the effectiveness summarised according to the criteria described above (Table 1).

Some evidence from randomised trials was available for only 31 of the 117 patient management questions. Moreover, there was sufficient evidence to allow some conclusions of effectiveness for particular interventions in only five of these. As shown in Table 2, there was sufficient evidence from four comparisons, featured in three questions, to conclude that a particular intervention was 'likely to be beneficial'. There was also sufficient evidence from two other comparisons to conclude that a particular intervention was 'unlikely to be beneficial'.

An extract from the full evidence document illustrating the format and type of information presented for questions where evidence was available is shown in Table 3. For pragmatic reasons, our evidence base was restricted to evidence from comparisons of treatment interventions. Nonetheless, in the coversheet of our evidence document (see 'Appendix 3 [see Additional file 3]') we referred to the 
Table 3: Extract from the evidence document

\begin{tabular}{ll}
\hline Q3.I When should definitive treatment begin? \\
\hline Evidence & Review [RI]: I RCT [TI], 80 participants \\
Aim /focus & Timing of primary manipulation of displaced Colles' fractures. \\
Population & Displaced Colles' fracture, age $>50$ years. No symptoms of median nerve compression. \\
Comparison & Delayed primary manipulation under regional anaesthesia at I week after back slab in displaced \\
& position versus immediate primary manipulation. \\
Outcome & Report of similar anatomical results in the two groups, with no increase in complications (median \\
& nerve compression) nor discomfort in the delayed manipulation group. \\
Comments & Insufficient information and no qualitative data available. Abstract only. \\
Interpretation & Unknown effectiveness
\end{tabular}

RI. Handoll HHG, Madhok R. Conservative interventions for treating distal radial fractures in adults (Cochrane Review). In: The Cochrane Library, Issue I, 2002. Oxford: Update Software. TI. McMillan J, James P, Kumar S, Kinninmonth AWG. Delayed primary manipulation of Colles' fractures - a prospective study [Abstract]. Injury 1996; 27(5):376.

serious problems associated with diagnosis, including fracture classification, and outcome assessment.

\section{The consultation}

The main body of the questionnaire was ordered according to the list of key questions associated with the eight care pathways. It provided a summary of the evidence and conclusions from the comprehensive evidence document, and was structured to enable separate commentary on the issues associated with individual questions and the research priority. People were requested to score the importance of further research according to three categories (2: high priority; 1 : worthwhile / moderate priority and 0: marginal / not needed). 'Appendix 4 [see Additional file 4]' shows an extract from the questionnaire. Also requested were a few personal details, including clinical involvement and experience, an overall view of research priorities and notification of any relevant research activities.

The majority $(60 \%)$ of the 48 people selected for participation had conducted one or more RCTs in this area. Personal contact and commendation identified some others, including the consumer representative. An internet search identified three other specialist UK orthopaedic and trauma consultants with a special interest in wrist fractures. We achieved a broad coverage of the specialties involved in the management of these fractures. Thus, included were specialist hand surgeons, A\&E specialists, orthopaedic and trauma surgeons, physicians with a known interest in osteoporosis, an anaesthetist, a casting specialist, specialist hand therapists and physiotherapists.

While over half (27) of the 48 people were based in the UK, 11 were based in other European countries, four in Australia and the other six in North America.
While a response to the invitation letter, sent to all 48 people at the beginning of August 2002, was only requested in those cases where the recipient felt unable to participate, 13 confirmed their interest and in four cases sent revised contact details. One interested recipient suggested approaching three others, one of whom was new to the list. Two people indicated that they did not wish to participate: one had changed his specialist area and the other was focusing only on clinical practice. However, further communication with the latter provided useful insights into his surgical treatment RCT conducted in the late 1980 s.

A covering letter plus enclosures, comprising the care pathways overview diagram ('Appendix 1 [see Additional file 1]'), the full care pathways document ('Appendix 2 [see Additional file 2]'), the compilation of the randomised evidence and the comprehensive questionnaire and summary document, was sent to 47 people in early October 2002. A reminder letter with a short research questionnaire was sent to 27 people in late November 2002.

The response received by 17 February 2003 is summarised in Table 4.

In all, some feedback was obtained from 28 people (60\%) of those approached. Half of these completed the questionnaire, while others generally provided feedback on specific topics falling within their expertise. Responders were still representative in that the broad coverage of specialities and membership of all the nations originally included had been maintained. The majority (25/28 $(89 \%))$ of respondents were, or had been at some stage of their career, directly involved in the clinical management of patients with distal radial fractures. Seven (25\%), including the consumer representative, reported that they or a close family member had sustained wrist fracture; in 
Table 4: Consultation group response

\begin{tabular}{lll}
\hline Response & Numbers & Percentage (of 47) \\
\hline Completed full questionnaire & 14 & $29.8 \%$ \\
Partially completed full questionnaire & 7 & $14.9 \%$ \\
Short research questionnaire only & 3 & $6.4 \%$ \\
Letter with comments & 4 & $8.5 \%$ \\
Letter abstaining from participation & 4 & $8.5 \%$ \\
Unknown address & 2 & $4.2 \%$ \\
No response / product & 13 & $27.7 \%$ \\
\hline
\end{tabular}

* Percentage rounded down so that total is $100 \%$

one case this was a fracture of the scaphoid rather than the distal radius.

\section{Processing the results of the consultation process}

Though the questionnaire succeeded in facilitating structured feedback, considerable processing was required to draw the maximum benefit from the varied and often insightful responses from the contributing members of the consultation group. We prepared three documents.

The first document was a compilation of the responses on individual treatment questions within the eight care pathways. Most responses were extracted ad-verbatim but some detective work was still required, typically for spelling-out abbreviations and referrals to previous comments on similar/related questions. Specific comments that were written in the research column, or were clearly research specific, were delineated by putting "Research:" at the start of the statement(s). Research ratings provided for each question were presented in tabular form. In a few cases research ratings were inferred from the comments on the individual or related questions, but generally the individual's box in the table was left blank when no rating was given. Note was also taken of instances where respondents had given different ratings for questions with multiple comparisons, such as methods of surgery.

Table 5, which is an extract, tailored for this report, from the first document, shows the responses for question Q3.1 (see Table 3 for the evidence for this question). As can be seen from this example, brief justifications of research ratings were often not provided; nor were specific research questions, though respondents were invited to provide both.

The second document summarised the responses for individual questions in terms of a) the issues raised and b) research implications. This was again structured by the individual questions within the eight care pathways. The differing natures of individual questions, and the variation in issues raised and often ratings of research priority, hindered a uniform approach. We strove to avoid zealous over-interpretation and aside from consistency checks (usually with related questions) retained an emphasis on people's own words and statements. Since the responses of two contributors indicated that it was very likely that they had misinterpreted the use of the research ratings, their scores were ignored for this compilation.

Table 6, which is an extract from the second document, shows the responses for Q3.1 (see Table 5 for the individual responses for this question).

Additional information, including feedback from the seven who did not complete the questionnaires, from respondents was placed into a third document. The available comments for each of the 28 respondents were sorted and placed into one of four categories: 'General'; 'Extra/ missing'; 'Research priority'; and 'Research activities'. Though, some included commentary was abridged, much of it was ad-verbatim. Some consistency checks were made, in particular for research priorities, and extra information added from subsequent contact with respondents especially regarding ongoing RCTs.

\section{Interpreting the results of the consultation process}

Our structured interpretation of the results of the consultation comprised three stages.

\section{Stage I: General issues concerning project aims, materials and} processes

The findings of the first phase are summarised in Table 7. One issue not described in Methods is our original plan to use two multi-staged consultations using the Delphi method [23] to identify the key decision points in the care pathways and research priorities. The Delphi method is an iterative, usually multi-staged, method of aggregating the judgements of a number of individuals, using a series of written questionnaires, in order to arrive at a consensus. Initial piloting by core group members of draft materials convinced us that changes to our original proposal were essential for the viability of the project. It is clear that, to 
Table 5: Modified extract from the document presenting the responses from individuals

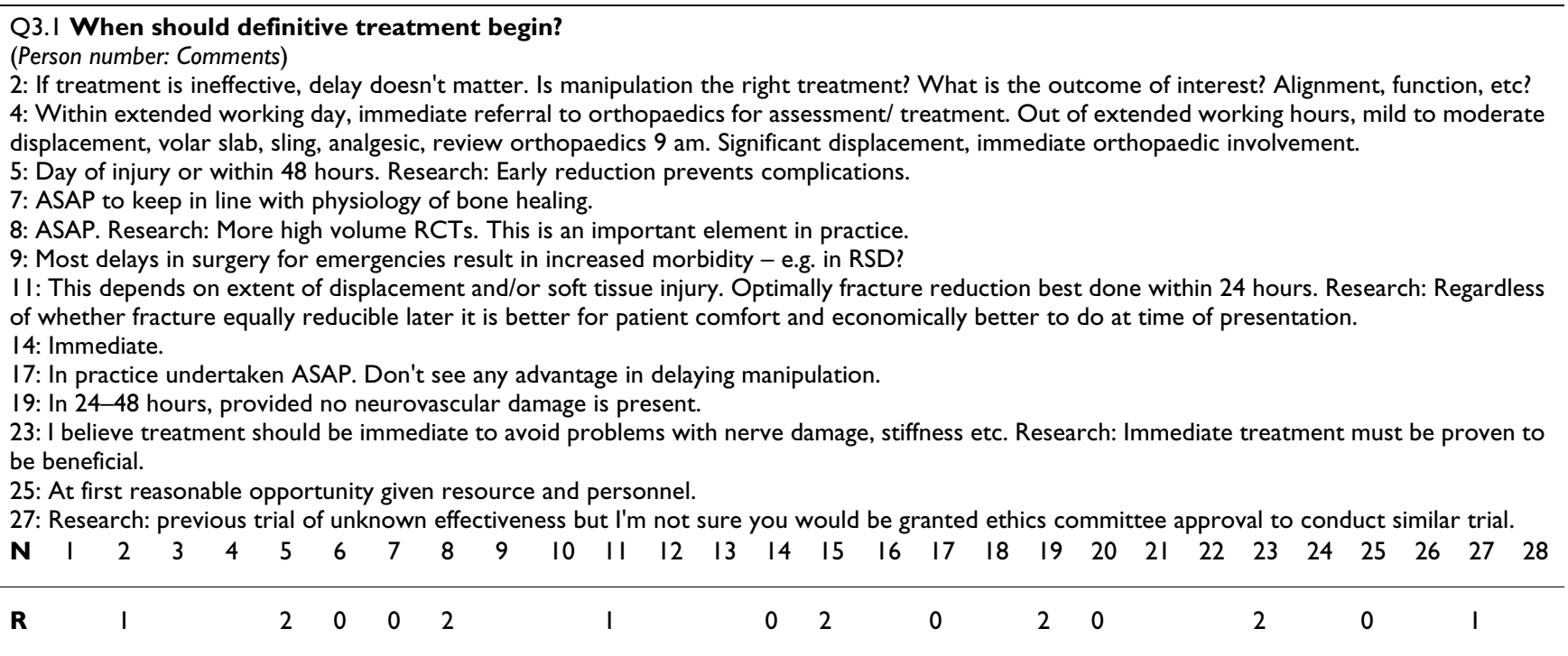

$N=$ Person number; $R$ = Research rating (see 'Appendix 4 [see Additional file 4]')

do full justice to the questions and issues, the one-stage consultation exercise was demanding. The planned Delphi consultations would have been excessive and are likely to have led to rapidly diminishing returns associated with participator fatigue.

Stage 2: Research priority topics from the list of patient management questions

Taken from the questionnaire alone, the research priority ratings for the 117 patient management questions ranged from 'no research', indicated for four questions, to a top priority rating (score $=2$ ) given by 12 people and a worthwhile rating (score $=1$ ) by a further two people for the question Q8: When is surgery indicated for definitive treatment (at start)? The research ratings for individual questions were adjusted according to the research priorities provided by six respondents who did not return the questionnaire.

In our examination of research priorities, we decided to limit the number of questions to a maximum of 20 and thus set a similarly arbitrary threshold of a minimum of five high priority scores. This resulted in 17 questions for which research on the question itself or, often, some aspect of the issues associated with the question was deemed high priority by five or more people (see Table 8 ). It also seemed appropriate to add in one other question (see Q5 in Table 8): this is because despite only four people giving it a high priority rating, a relatively high number (nine) considered it worthwhile. A concise summary of the evidence available, as presented in the questionnaire, for each of the 18 questions is shown in
'Appendix 5 [see Additional file 5]'. Clearly, this exercise ignores the interdependency, to varying extents, of these questions with each other as well as with other questions in the care pathways.

\section{Stage 3: Some exploration of the feedback in terms of basic} questions

Here, we examined the main messages and research priorities listed by the consultation group members in the context of four underlying questions (for whom, what, when and who by?) and attempted to identify core themes and issues.

\section{For whom?}

It was clear that all respondents generally focussed on 'typical Colles' fracture patients'. Even thus limited, there is much variation in patient and fracture characteristics. Also clear from the feedback was that how much, and in what ways, the individual characteristics of the patient and their injury influence management decisions varies considerably, according to both the treatment question and the perspective of the respondent.

Overall, several key issues emerged from the consultation group feedback.

One fundamental issue, of long-term and continuing controversy, remains the relationship between fracture position/pattern and outcome. Among related issues are a) 'acceptable' deformity, that is pain-free cosmetic deformity that does not impact on a person's function, and b) fracture instability. The latter was considered in various 
Table 6: Extract from the document summarising the responses from individuals

\section{Q3.I When should definitive treatment begin?}

Issues

Immediate or as soon as possible commencement of definitive treatment, commonly addressed in terms of the need for fracture manipulation, was proposed by seven of the 13 commentators. A further three commentators gave time limits, either within first 24 or 48 hours; one of these implied that there should be no delay if neurovascular damage was present. Reasons put forward for treatment without delay were: consistency with physiology of bone healing, avoidance of complications, significant displacement, surgical delay for emergencies resulting in increased morbidity, patient comfort, and less costly. One respondent, who advocated immediate treatment, suggested less urgency for undisplaced fractures. One respondent proposed a more pragmatic approach ("at first reasonable opportunity given resource and personnel") and one pointed out that if the treatment is ineffective any delay was immaterial and queried "Is manipulation the right treatment?"

Research

Four respondents indicated that research on this was a top priority and three others indicated that it would be worthwhile. Two respondents indicated only that the question was important, and one other that research was worthwhile provided the treatment was of proven effectiveness. The choice of a specific research issue may have been influenced by the comparison tested in the one available RCT. Evaluation of effects (e.g. avoiding complications, patient comfort, costs) of immediate or early treatment (probably, reduction of displaced fractures) was proposed as a research priority by three respondents, and as worthwhile by two others. One respondent suggested that gaining ethical approval for a trial of delayed reduction, similar to the one reviewed, would be difficult.

Table 7: Summary and interpretation of the feedback on general issues from the consultation process

\begin{tabular}{|c|c|c|c|}
\hline & Question & Processing & Conclusion \\
\hline i & $\begin{array}{l}\text { Were the overall aims of the } \\
\text { initiative acceptable? }\end{array}$ & $\begin{array}{l}\text { No direct question: answer deduced from actions taken by } \\
\text { responders and the lack of contrary statements. }\end{array}$ & Yes: no contrary evidence. \\
\hline ii & $\begin{array}{l}\text { Was the consultation group } \\
\text { representative? }\end{array}$ & $\begin{array}{l}\text { This depends on the reference population and the validity of the } \\
\text { criteria used to define the key characteristics of such a group. } \\
\text { Our non-validated inclusion criteria were met in that the group } \\
\text { included, with the exception of a special-interest general } \\
\text { practitioner (GP), all relevant clinical specialities, confirmed } \\
\text { active researchers, opinion leaders and a consumer } \\
\text { representative. }\end{array}$ & $\begin{array}{l}\text { Probably, no. However, the absence of a GP aside, the } \\
\text { group members provided clinical coverage of the whole } \\
\text { care programme and would be influential in setting and } \\
\text { enacting the future research agenda. }\end{array}$ \\
\hline iii & $\begin{array}{l}\text { Was the care pathways scheme } \\
\text { acceptable? }\end{array}$ & $\begin{array}{l}\text { No direct question though general comments invited. No } \\
\text { criticisms on overall scheme including basic structure. However, } \\
\text { some suggestions for a) specific inclusion of risk assessment for } \\
\text { future fractures and subsequent medical management, b) } \\
\text { management of chronic regional pain syndrome type I (RSD), } \\
\text { and c) specialist centres for secondary treatment. }\end{array}$ & $\begin{array}{l}\text { Yes, overall. Suggestions for explicit development of } \\
\text { secondary prevention pathway, management of RSD and } \\
\text { specialist intervention for secondary treatment. }\end{array}$ \\
\hline iv & $\begin{array}{l}\text { Was the presentation of the } \\
\text { decision points in terms of } \\
\text { treatment questions acceptable? }\end{array}$ & $\begin{array}{l}\text { No direct question. Answer deduced from lack of contrary } \\
\text { statements. One respondent suggested a move to a decision-tree } \\
\text { format. Another suggested better definition of care provider } \\
\text { questions in terms of action and decision making. }\end{array}$ & Yes, overall. \\
\hline $\mathrm{v}$ & $\begin{array}{l}\text { Was restricting the project evidence } \\
\text { base to that presented in the five } \\
\text { Cochrane reviews a reasonable } \\
\text { compromise? }\end{array}$ & $\begin{array}{l}\text { There was no direct overall criticism of our decision to confine } \\
\text { our remit to RCTs within our five reviews, and from their } \\
\text { responses, people clearly were not constrained to RCT } \\
\text { evidence. However, some respondents stressed that RCTs are } \\
\text { not always appropriate. There was also some call for evidence } \\
\text { from other clinical areas. In addition, some respondents indicated } \\
\text { that consideration of outcome measurement and the association } \\
\text { of fracture classification/position with clinical outcome was } \\
\text { missing. }\end{array}$ & $\begin{array}{l}\text { Yes, generally. However, other study designs are more } \\
\text { appropriate for some issues, and some other issues } \\
\text { could be informed by evidence from other subjects (e.g. } \\
\text { wound care). Also considered missing was evidence from } \\
\text { studies on prognosis and outcome measurement. }\end{array}$ \\
\hline vi & $\begin{array}{l}\text { Were the interpretation and } \\
\text { presentation of the evidence } \\
\text { considered valid? }\end{array}$ & $\begin{array}{l}\text { No explicit comment received on structure and contents of the } \\
\text { evidence document, including choice of effectiveness categories } \\
\text { scheme. Many took the interpretation of evidence 'as a given'. } \\
\text { There were instances where respondent's judgement of the } \\
\text { available evidence differed from ours; usually where we } \\
\text { considered there was insufficient evidence to draw a conclusion } \\
\text { of effectiveness or lack of effectiveness. }\end{array}$ & $\begin{array}{l}\text { Yes, probably given the absence of direct comments and } \\
\text { since the summary statements were often used as a basis } \\
\text { for feedback. However, there were some differences - } \\
\text { our interpretation of the evidence was usually more } \\
\text { cautious. }\end{array}$ \\
\hline vii & $\begin{array}{l}\text { Was the questionnaire design } \\
\text { acceptable and did it facilitate } \\
\text { feedback? }\end{array}$ & $\begin{array}{l}\text { Some respondents, who indicated that the full questionnaire was } \\
\text { too much, were encouraged to at least comment on research } \\
\text { priorities. Others felt more comfortable completing only the } \\
\text { questions within their professional domain. Equivalent questions } \\
\text { on parallel pathways were probably irksome to some } \\
\text { respondents but an alternative approach would have lost the } \\
\text { consistent presentation of questions in the project } \\
\text { documentation. The wording for some questions was sub- } \\
\text { optimal. }\end{array}$ & $\begin{array}{l}\text { Yes in that some quality feedback was obtained but with } \\
\text { some serious reservations. }\end{array}$ \\
\hline viii & $\begin{array}{l}\text { Was the single consultation exercise } \\
\text { a reasonable substitute for the } \\
\text { originally envisaged two stage Delphi } \\
\text { consultation? }\end{array}$ & $\begin{array}{l}\text { Given the excessive demands on consultation group members, it } \\
\text { is unlikely that multi-staged consensus process would have } \\
\text { worked or achieved equivalent or superior results to the actual } \\
\text { methods applied. }\end{array}$ & Yes, the pragmatic alternative appeared more viable. \\
\hline
\end{tabular}


Table 8: Provisional list of 18 top priority research areas from the list of patient management questions

\begin{tabular}{|c|c|c|c|}
\hline No. & $\begin{array}{l}\text { Question (Numbering from project materials } \\
\text { including the questionnaire) }\end{array}$ & $\begin{array}{l}\text { Pathway See 'Appendix I [see Additional } \\
\text { file I]' }\end{array}$ & No. of high priority scores * \\
\hline 1 & $\begin{array}{l}\text { Q4 When is reduction (non surgical or surgical) } \\
\text { required? }\end{array}$ & Core: reduce? & 11 \\
\hline 2 & $\begin{array}{l}\text { Q5 Is immobilisation of the injured wrist for any } \\
\text { duration necessary for undisplaced (or minimally } \\
\text { displaced) fractures? }\end{array}$ & Core: immobilise non-reduced fracture? & $4 \dagger$ \\
\hline 3 & $\begin{array}{l}\text { Q7.7 How long should the wrist be immobilised } \\
\text { (undisplaced / minimally displaced fractures)? }\end{array}$ & Path 2: non-reduced, immobilised fractures & 7 \\
\hline 4 & $\begin{array}{l}\text { Q7.II What rehabilitation interventions should be } \\
\text { given at this stage (post immobilisation)? }\end{array}$ & Path 2: non-reduced, immobilised fractures & $7^{*}$ \\
\hline 5 & $\begin{array}{l}\text { Q8 When is surgery indicated for definitive treatment } \\
\text { (at start)? }\end{array}$ & Core: surgery? & 12 \\
\hline 6 & $\begin{array}{l}\text { Q9.6 What is the preferred immediate treatment } \\
\text { option if reduction is immediately unsuccessful? }\end{array}$ & Core: closed reduction & 5 \\
\hline 7 & $\begin{array}{l}\text { Q13.2 What type of immobilisation is required for } \\
\text { reduced initially displaced fractures? }\end{array}$ & $\begin{array}{l}\text { Path 3: reduced displaced fracture, } \\
\text { conservative treatment }\end{array}$ & 6 \\
\hline 8 & $\begin{array}{l}\text { Q13.5 What rehabilitation interventions should be } \\
\text { given at this stage (during immobilisation)? }\end{array}$ & $\begin{array}{l}\text { Path 3: reduced displaced fracture, } \\
\text { conservative treatment }\end{array}$ & $5^{*}$ \\
\hline 9 & $\begin{array}{l}\text { Q13.7 How long should the wrist be immobilised for } \\
\text { reduced fractures? }\end{array}$ & $\begin{array}{l}\text { Path 3: reduced displaced fracture, } \\
\text { conservative treatment }\end{array}$ & 6 \\
\hline 10 & $\begin{array}{l}\text { Q13.II What rehabilitation interventions should be } \\
\text { given at this stage (post-immobilisation)? }\end{array}$ & $\begin{array}{l}\text { Path 3: reduced displaced fracture, } \\
\text { conservative treatment }\end{array}$ & $11 *$ \\
\hline 11 & $\begin{array}{l}\text { Q I4 What method(s) of surgery (could be a } \\
\text { combination) are preferable for typical circumstances } \\
\text { (fracture types)? }\end{array}$ & Core: reduce fracture, surgical treatment & 8 \\
\hline 12 & $\begin{array}{l}\text { Q 18.I What method(s) of external fixation is / are } \\
\text { preferable? }\end{array}$ & Path 5: external fixation & 5 \\
\hline 13 & $\begin{array}{l}\text { Q19.I What method(s) of internal fixation is / are } \\
\text { preferable? }\end{array}$ & Path 6 (incomplete): internal fixation & 6 \\
\hline 14 & $\begin{array}{l}\text { Q19.2 Is triangular ligament repair necessary (internal } \\
\text { fixation)? }\end{array}$ & Path 6 (incomplete): internal fixation & 5 \\
\hline 15 & $\begin{array}{l}\text { Q20.I What materials for filling bony defects are } \\
\text { acceptable? }\end{array}$ & Path 7 (incomplete): bone scaffolding & 7 \\
\hline 16 & $\begin{array}{l}\text { Q21.3 When should (re-) reduction be done for re- } \\
\text { displaced / secondarily displaced fractures? }\end{array}$ & Core: significant loss of position & 5 \\
\hline 17 & $\begin{array}{l}\text { Q23.2 What are good (practical and effective) ways of } \\
\text { (routinely) delivering rehabilitative interventions? }\end{array}$ & Core: other rehabilitation & $7^{*}$ \\
\hline 18 & $\begin{array}{l}\text { Q23.4 What intervention(s) should be routinely } \\
\text { provided aimed at secondary prevention? For example, } \\
\text { should patients be screened for osteoporosis? }\end{array}$ & Core: other rehabilitation & $6^{*}$ \\
\hline
\end{tabular}

* Adjusted rating; $†$ Exception made since 9 people also indicated that research would be worthwhile

ways. For instance, a) how often minimally displaced fractures subsequently displaced, b) late displacement of fractures, post-immobilisation, and c) identification, definition and prediction of unstable fractures.

There was some call for the determination of prognostic indicators of outcome for various types of fractures, usually taking account of other patient characteristics. One respondent proposed "long term outcome studies of various treatments, informed by existing knowledge of case series, especially for displaced and intra-articular fractures, controlled for bone density and patient comorbidity/ quality of life". A suggestion for specific focus was on the involvement of the DRUJ (distal radio-ulnar joint).
Others proposed the identification of predictors to identify patients likely to do badly, including those at risk of complications during treatment who would require further treatment including more extensive rehabilitation.

Linked with the above and important overall is measurement, an essential component of research. A few respondents, one of whom was researching an "automated fracture classification system", mentioned classification of fractures but most respondents raising this issue considered assessment of outcome. One respondent pointed to a "desperate need" for a "consensus on what outcome measures are relevant, in which circumstances, and valid measures in general." Another detailed research on "vali- 
dated outcome tool specific for older individual functional needs and functional status pre-injury", and a further respondent planned research on "applicability, reliability, validity and responsiveness of some instruments for evaluation of pain, function, self-efficacy, fearavoidance and life satisfaction after Colles' fracture (impairment $\&$ disabilities)". As well as standardisation of outcome, there was some emphasis on patient related evaluation of outcome and what matters to patients. There was some emphasis on assessing outcome during the treatment/recovery process, in part to identify "good functional result at different times after the fracture".

Various patient characteristics and attributes were also mentioned that would/could affect outcome. These included patient motivation and ability to cope and adapt, understanding and memory of advice and instructions, comfort and tolerance of splintage, and patient needs, (including values and preferences), activities and circumstances. Compliance also featured along with "trust" and (realistic) expectations of both patients and clinicians.

\section{What?}

This question was the main focus of the questionnaire and project materials. Two key issues associated with this question were a) the need for and extent of immobilisation and $b$ ) resource use.

One respondent, a rehabilitation specialist, felt that "there might have been far too much emphasis in the literature on 'hold' and 'reduce' with these fractures, and not nearly enough on the third principle of fracture management, 'move'." Certainly the feedback from the consultation group revealed different emphasises on stabilisation of fractures, to let the fracture heal without further displacement/re-displacement, and mobilisation to avoid/lessen the complications of immobilisation and to enable earlier functional recovery.

There were calls for evaluation of the economics of injury and methods of treatment, and the cost implications of the care pathways. Resource use also applies to the Who by? question, the only specific issue considered here being the routine provision of specialist rehabilitation. One respondent expressed her thoughts as follows: "Identifying which patients need rehabilitation, by whom and where (local health centres were quite reluctant to treat our patients for any length of time as they felt their waiting lists were too long and priority was given to backs/ necks etc). Cost effectiveness analyses should also be incorporated into the study."

\section{When?}

Questions of timing, namely when to start various interventions/monitoring, how often and for how long, were also well covered in the questionnaire and project materials. One key issue was duration of immobilisation; this is discussed above. Another issue was timing of definitive treatment in the context of a) neurovascular compromise and b) the healing process / underlying biology, specifically the window of opportunity for reduction, remedial intervention e.g. re-reduction and/or surgery. The extension of care to secondary prevention could also come under this category.

\section{Who by?}

Thirty-six management questions directly addressed this basic issue for various aspects of patient care. To various degrees, the comments - and sometimes whether they were provided at all - to specific 'who?' questions were dependent on context and the answers to preceding questions. However, and more so for rehabilitation questions, the answers provided by individual respondents for questions presented for many pathways were usually similar and sometimes cross-referred.

The following general point made by one respondent indicated some of the underlying issues: " 'Who should do' question is incomplete unless you specify whether the person doing is also making the diagnosis and indication, or simply acting on the decision of someone else." Rather than the provision of care, some questions focussed on 'Who was suitable to decide' issues; and here, another respondent considered that "Regardless of health system, responsibility should remain with MD (doctor) who makes decisions." Some others also drew attention to teamwork. For example, one respondent referred to the administration of standard rehabilitation advice by any member of the MDT (multidisciplinary team). Another respondent, who gave instances where different members of the team gave diverging information and advice to the same patient, considered that the study of teamwork during rehabilitation was a research priority. As well as provision of care under supervision, or under direction, aspects of training and specific expertise also featured in the responses. Much of the latter could be inferred from the profession/discipline listed by the respondents.

Aside from the above, a major issue arising from consultation group feedback was specialist versus generalist care.

One respondent, an orthopaedic surgeon, made his case for specialist involvement as follows: "Totally inappropriate care for $A \& E$ staff to manipulate a fracture for orthopaedics before orthopaedic further review. No audit capacity and quite out of step with normal speciality working practices. A\&E should identify a problem with 
the support speciality treating from the outset and auditing the effect of their intervention." Further on when addressing question Q6.8 (Who is suitable to examine the patient (with undisplaced fractures)?), the same respondent chose "The doctor" and justified this as follows "Enough of the cases go wrong to justify that level of involvement. Colles fracture is one of the biggest compensation issues in upper limb practice and I believe the time has come to recognise the changing expectations in those who suffer from Colles fractures." The responses from some others showed acceptance of other professions and/ or less specialist care; one sent a copy of a report of their research on a nurse-led fracture review service. In most cases there was some mention of appropriate skills and training. We have already raised the issue of specialist rehabilitation. A further comment, based on practice in Australia, was "frequently new graduates [physiotherapists] are treating these patients in public hospitals and results may be different with experienced physiotherapists".

Taking a broad perspective, one respondent queried: "Is there a need for a tertiary centre for secondary therapy physiotherapy or surgical? - are the numbers small enough in a secondary setting yet manageable in a tertiary setting?" There are clear resource implications for this and 'who by?' questions in general, including, as implied above, potential medico-legal costs.

\section{Discussion}

The results and products of this project have moved us some way towards our ultimate aim, namely the development of an evidence-based and patient-centred care programme for patients with distal radius fractures. However, despite a wealth of insights drawn from an extensive consultation with some of the key players in this area, we decided that we had insufficient material to achieve our interim objective of developing a research agenda, even a provisional one. Nonetheless, there are certainly strong pointers to some consensual research priorities. Moreover, the project materials form a comprehensive evidence base and strategic basis that can facilitate further advance towards our shared, and clearly endorsed, aims.

\section{Observations on the evidence base}

The availability of five systematic reviews covering all the key interventions for the management of these fractures is an achievement, and one enhanced by the proven commitment to updating the reviews in the light of new evidence. We acknowledge that our decision to restrict the evidence to that from randomised trials is a pragmatic one and that other study designs are often more appropriate for assessing some aspects of management [24]. Nonetheless, one of the key outcomes of our reviews is the demonstration of the overall inadequacy of the evidence from randomised trials in informing most of the treatment decisions for these fractures. And it is very likely that the evidence for treatment interventions is even more defective from other types of studies where the strong possibility of selection bias, which random allocation attempts to counter, compounds the risk of other systematic and random biases.

The collaboration and feedback from members of the consultation group implied their acceptance of the aims of the project and support for the care pathways scheme we developed for 'typical' fractures and the associated presentation of decision points in terms of over 100 management questions. There was very little direct feedback on our comprehensive evidence document which, via systematic processes, distilled and interpreted the findings of our reviews. Nonetheless, as well as fulfilling one of the targets of our project, the availability of such a document again constitutes a real advance. The summaries of the evidence base given in the questionnaires will have also helped to disseminate the important findings of our reviews.

\section{Limitations of the consultation exercise}

Without doubt, the abandonment of our original plans for a two stage Delphi consultation undermined the potential to deliver a consensus document, specifically a research agenda. We are, however, convinced that our alternative approach for consultation engendered a better response and generated valuable insights that will serve to progress this complex and problematic area. From our perusal of the feedback received, we suggest that a high level of agreement would have been unlikely; and thus the findings would have shifted to an appraisal of the extent of disagreement. Even then, the validity of a quantitative assessment of agreement could be questioned, as could the absence of any proven link between agreement and veracity. Though a future consultation, based on Delphi methods, aiming to move towards consensus or, at least, give a clearer depiction of the disparity in opinion, should not be ruled out, it would need to be very focused and limited in its scope to ensure a good response.

It is impossible to determine how representative the results of our consultation are and the possible extent and impact of bias, including that arising from the incomplete response to the questionnaire. While, retrospectively, we realise that we should have sought comments from a general practitioner, the composition of the consultation group met our prior inclusion criteria. The consultation group thus included members of the key professions managing these fractures, a patient representative, opinion leaders and active researchers. Inevitably, the composition of our group and the variation in the completeness of responses from specific representatives will have distorted 
some of the findings. This is an inherent flaw in this sort of study. However, we consider the findings of this project, based on careful interpretation, are valuable and represent an advance in knowledge.

\section{Messages for practice and research}

Some messages for practice and research can be gleaned from the feedback from the consultation group. Some of these, such as awareness of deficiencies in outcome measurement and of the potential for risk-assessment for future fractures, could be viewed as encouraging. It is noteworthy that, given the primary focus on the specific management of these fractures in the care pathways scheme, several respondents indicated that more attention needed to be paid to secondary prevention and the underlying causes of fractures. Other messages, such as questions over the relationship between fracture position/pattern and outcome, and of 'acceptable' deformity, show that some of the fundamental and long-term controversies remain unresolved.

Though we stress that we consider we have insufficient grounds for presenting a research agenda, we consider that the available feedback does give some pointers to research priorities. Partly, this is supported by the fact that none of the 18 entries in the provisional list of top priority areas for research came as a surprise to us (see Table 8) and that RCTs had been conducted for the majority (13) of these (see 'Appendix 5 [see Additional file 5]'). We suggest, however, that some consideration needs to be given to the intended population. For example, it is likely that comparisons of methods of internal fixation are less likely to focus on our target population of 'typical' Colles' fracture patients.

Related issues and questions arose from our examination of the feedback in terms of basic questions. Many of the issues identified in stage 3 of our interpretation of the feedback are fundamental to management decisions. An example of a basic factor is 'acceptable' deformity, which may for some be an underlying rationale for predominantly conservative treatment, and earlier mobilisation, provided functionality is not compromised. As pointed out above, the exact relationship between anatomy and functional/clinical outcome was explicitly questioned by some clinicians. Some issues, such as the focus on outcome measurement, are also pertinent to how the existing evidence is perceived as well as guides to future research methodology.

\section{Care providers and practice}

In our compilation of management questions, we consistently included questions on care providers; including those who took the decisions and were responsible for the overall treatment plan. The responses often revealed a broad range of opinion that, to some extent, can be categorised by the specialist versus the generalist question, in particular for definitive treatment. There are clearly considerable resource implications associated with any substantive increase in specialist care given that this is a commonly occurring fracture. There is also a question of the quality of care provided. For example, do people with these fractures receive sub-optimal care, perhaps by under-supervised and under-experienced personnel, in the emergency room setting? One respondent emphasised that Colles' fracture is one of the biggest compensation issues in upper limb practice. A recently published analysis of orthopaedic liability in acute care settings in the USA backs this up and also revealed that many orthopaedic surgeons in the USA purposefully restricted their involvement in emergency settings in order to the "minimize or eliminate their exposure to emergency department risk"[25]. Another important aspect is communication, both between patient and clinician and between clinicians. An example of an unsatisfactory situation was an account of instances where different members of the team gave divergent information and advice to the same patient.

The above also demonstrates, perhaps indirectly, a benefit of our approach, where we asked people to address both practice and research implications at the same time. Some of the feedback dwelt upon research methods and potential applicability of research findings. As well as this indication that research and the results of research need to be set into the context of actual practice, there was also, as exemplified by the focus on functional and patient rated outcome assessment, some emphasis on differences that matter to patients.

\section{Conclusions}

The products of this project are a substantive advance towards the development of an evidence-based and patient-centred care programme for patients with distal radius fractures.

By themselves, the five systematic reviews covering all the key interventions specific to this area, the care programme schemata showing key management questions, and the comprehensive evidence document summarising the evidence available for each decision point form a strong basis and structure for future work. The matching of the evidence available from RCTs, specific for these fractures, to the key management questions emphasises the paucity in the evidence for reliably informing management decisions. There is very little to inform on what works, or what doesn't work, and for whom.

As discussed, our consultation method had important limitations, expressly in the questions over the represen- 
tiveness of the participants, the incapacity for working towards a consensus or quantitative estimates of agreement/disagreement, and the application of arbitrary thresholds. Nonetheless, a careful and systematic interpretation of feedback from key players in the field yielded valuable insights on current practice and important pointers for future developments and research. The provisional list of top priority areas for research shows a demand to get answers for key questions, many already the focus of previous RCTs, such as: when is reduction required; for how long is immobilisation needed; when and what type of surgery is indicated; and what type of rehabilitation is required post immobilisation? Examination of the feedback also revealed several underlying issues/themes. These included the relationship between fracture pattern and outcome, 'acceptable' deformity, valid outcome measures reflecting what matters to patients, patient motivation and expectations, fracture stabilisation versus early mobilisation, effective teamwork and specialist versus generalist care. There were also indications of greater awareness and emphasis on the implications of these fractures in terms of osteoporosis and prevention of further fractures.

We anticipate that the consultation and the resulting messages should enhance the prospects for collaborative and better quality research and, eventually, practice.

\section{List of abbreviations}

ASAP: as soon as possible

\section{GP: general practitioner}

RCT: randomised controlled trial

RSD: reflex sympathetic dystrophy. Also referred to as algodystrophy, Sudeck's atrophy, complex regional pain syndrome type 1 and shoulder-hand syndrome

\section{Competing interests}

None declared.

\section{Authors' contributions}

$\mathrm{HH}$ is the primary author and RM the second author of all five Cochrane reviews that formed the evidence base for this project. HH was the paid researcher on the project and designed and produced, with critical input from RM and others, all the documentation for the project, and processed and interpreted the feedback from the consultation exercise, and drafted the study report. RM suggested the study and provided critical input at all stages. Both authors read and approved the final manuscript.

\section{Additional material}

\section{Additional File 1}

Appendix 1 Care pathways for 'typical' fractures of the distal radius in adults (simplified diagram)

Click here for file

[http://www.biomedcentral.com/content/supplementary/1471-

2474-4-27-S1.doc]

\section{Additional File 2}

Appendix 2 Usual treatment pathways for 'typical' fractures of the distal radius in adults

Click here for file

[http://www.biomedcentral.com/content/supplementary/1471-

2474-4-27-S2.doc]

\section{Additional File 3}

Appendix 3 Extract from the evidence document (Compilation of evidence from randomised trials) coversheet on general methodological issues Click here for file

[http://www.biomedcentral.com/content/supplementary/14712474-4-27-S3.doc]

\section{Additional File 4}

Appendix 4 Extract from questionnaire

Click here for file

[http://www.biomedcentral.com/content/supplementary/1471-

2474-4-27-S4.doc]

\section{Additional File 5}

Appendix 5 Evidence from RCTs associated with the provisional list of 18 top priority research areas (see Table 8 )

Click here for file

[http://www.biomedcentral.com/content/supplementary/14712474-4-27-S5.doc]

\section{Acknowledgements}

Part funding for this project was received from the National Osteoporosis Society (UK) for the period May 2002 to end of April 2003.

The core group members of the project were: Helen Handoll (project researcher), Rajan Madhok (lead grant applicant), Tracey Howe (co-applicant), John Fordham (co-applicant), John Stothard (main clinical consultant) and Kate Rowntree (administrative assistant).

The consultation group members were: Per Adolphson, Peter Amadio, Roma Bhopal, Frank Burke, William Cooney, Tim Davis, Joe Dias, Chris Dodds, John Fordham, Tracey Howe, Jesse Jupiter, John Kanis, Sandra Kay, Philippe Kopylov, Jegan Krishnan, Christel Lagerström, Samit Mitra, Terence O'Neill, Christine Phillips, Carlos Rodríguez-Merchán, John Stothard, Iris Swain, Nicholas Taylor, Alison Wakefield, W Angus Wallace, David Warwick, Alison Wigg, Claire Young and Chris Wardman.

The authors thank all of the above for their input into the project as well as the editors and other members of the editorial team of the Cochrane Musculoskeletal Injuries Group and external referees for their constructive input into the five Cochrane reviews. We are also grateful to Emma Veitch for her very helpful suggestions on improvements to the presentation of this paper. 


\section{References}

I. Sahlin Y: Occurrence of fractures in a defined population: a Iyear study. Injury 1990, 21:158-160.

2. Singer BR, McLauchlan GJ, Robinson CM, Christie J: Epidemiology of fractures in 15,000 adults: the influence of age and gender. J Bone Joint Surg Br 1998, 80:243-248.

3. Cummings SR, Kelsey JL, Nevitt MC, O'Dowd KJ: Epidemiology of osteoporosis and osteoporotic fractures. Epidemiol Rev 1985, 7:178-208

4. O'Neill TW, Cooper C, Finn JD, Lunt M, Purdie D, Reid DM, Rowe $R$, Woolf $A D$, Wallace WA, on behalf of the UK Colles' Fracture Study Group: Incidence of distal forearm fracture in British men and women. Osteoporos Int 200I, I 2:555-558.

5. National Osteoporosis Society: Accidents, falls, fractures and osteoporosis. A Primary Care Service Framework for Osteoporosis. London 1999.

6. Nguyen TV, Center JR, Sambrook PN, Eisman JA: Risk factors for proximal humerus, forearm, and wrist fractures in elderly men and women. The Dubbo Osteoporosis Epidemiology Study. Am J Epidemiol 200I, 153:587-595.

7. Chitnavis ]: The wrist. In Classification of musculoskeletal trauma Edited by: Pynsent PB, Fairbank JCT, Carr AJ. Oxford: Butterworth Heinemann; 1999:146-170.

8. Bacorn RW, Kurtzke JF: Colles fracture. A study of two thousand cases from the New York State Workmen's Compensation Board. J Bone Joint Surg Am 1953, 35:643-658.

9. Gartland J], Werley CW: Evaluation of healed Colles' fractures. J Bone Joint Surg Am I95I, 33:895-9|0.

10. Cooney WP 3rd, Dobyns JH, Linscheid RL: Complications of Colles' fractures. J Bone Joint Surg Am 1980, 62:613-619.

II. Scaf-Klomp W, van Sonderen E, Danderman R, Ormel J, Kempen GIJM: Recovery of physical function after limb injuries in independent older people living at home. Age Ageing 200I, 30:213-219.

12. Handoll HHG, Madhok R: Conservative interventions for treating distal radial fractures in adults. Cochrane Database Syst Rev 2003:CD0003 I4.

13. Handoll HHG, Madhok R: Closed reduction methods for treating distal radial fracture in adults. Cochrane Database Syst Rev 2003:CD003763.

14. Handoll HHG, Madhok R: Surgical interventions for treating distal radial fractures in adults. Cochrane Database Syst Rev 2003:CD003209.

15. Handoll HH, Madhok R, Dodds C: Anaesthesia for treating distal radial fracture in adults. Cochrane Database Syst Rev 2002:CD003320.

16. Handoll HH, Madhok R, Howe TE: Rehabilitation for distal radial fractures in adults. Cochrane Database Syst Rev 2002:CD003324.

17. Handoll HHG, Madhok R: Pitfalls in research: insights from studies of treatment of distal radius fractures in adults. Curr Orthop 200I, 15:388-393.

18. Handoll HHG, Madhok R: Managing fractures of the distal radius in adults. Clinical and research implications from systematic reviews of existing trials. Acta Orthop Scand Suppl 2002, 305:45-48.

19. Royal College of Physicians: Osteoporosis. Clinical guidelines for prevention and treatment. London 1999.

20. The Cochrane Collaboration: Cochrane Reviewers' Handbook 4.I [updated June 2000]. In Review Manager (RevMan) [Computer program]. Version 4.I Edited by: Clarke M, Oxman AD. Oxford, UK; 2000.

21. Fernandez DL, Jupiter JB: Fractures of the distal radius. A practical approach to management New York: Springer-Verlag; 1996.

22. Clinical Evidence online [http://www.clinicalevidence.org]

23. Delbecq AL, van de Ven AH, Gustafson DH: Group techniques for program planning. A guide to nominal group and Delphi processes Glenview, Illinois: Scott, Foresman and Company; 1975.

24. Sackett $D L$, Wennberg JE: Choosing the best research design for each question. $B M J$ 1997, 3 I 5:1636.

25. Gould MT, Langworthy MJ, Santore R, Provencher MT: An analysis of orthopaedic liability in the acute care setting. Clin Orthop 2003, 407:59-66.

\section{Pre-publication history}

The pre-publication history for this paper can be accessed here: http://www.biomedcentral.com/1471-2474/4/27/prepub

Publish with Bio Med Central and every scientist can read your work free of charge

"BioMed Central will be the most significant development for disseminating the results of biomedical research in our lifetime. "

Sir Paul Nurse, Cancer Research UK

Your research papers will be:

- available free of charge to the entire biomedical community

- peer reviewed and published immediately upon acceptance

- cited in PubMed and archived on PubMed Central

- yours - you keep the copyright

BioMedcentral 